\title{
Blunt Thoracic Aortic Injuries: New Perspectives in Management
}

\author{
Dimitrios Challoumas ${ }^{1}$ and Georgios Dimitrakakis, ${ }^{2, *}$ \\ ${ }^{1}$ Department of Upper GI Surgery, Gloucestershire Royal Hospital, Great Western Road, Gloucester, GL1 3NN, UK \\ ${ }^{2}$ Department of Cardiothoracic Surgery, Univers ity Hospital of Wales, Heath Park Campus, Cardiff, CF $144 X W, U K$
}

\begin{abstract}
Blunt thoracic aortic injuries (BTAIs) present a great challenge because of their potentially fatal outcomes. Recent advancements in their management have proved to be beneficial in terms of various parameters, including mortality and complications. Endovascular repair is now the treatment of choice in most centres and is continuously replacing the traditional open surgical method. We present a mini-review of the most recent relevant literature that briefly describes the major shifts in the diagnosis and treatment of BTAIs and compares the outcomes of the conventional surgical approach to those of the endovascular method for the definitive repair of these injuries. Although both the reviewed literature and the most recently published guidelines are in support of the use of the endovascular approach, as short and midterm results are promising, its long-term outcomes still remain in question.
\end{abstract}

Keywords: Blunt thoracic aortic injury, cardiovascular surgery, endovascular repair, delayed repair, open repair, trauma..

\section{BACKGROUND}

Blunt thoracic aortic injuries (BTAIs) are the second leading cause of death from blunt trauma after head injury and although they account for less than $1 \%$ of trauma admissions, they have significantly high morbidity and mortality rates. Pre-hospital mortality is as high as $85 \%$ and even of the remaining $15 \%$, a third will die before interventional treatment is provided [1,2].

Arthurs and colleagues (2009), analysing data from the National Trauma Data Bank, found that, in a 5 year period, 3114 patients suffered a BTAI, representing $0.3 \%$ of all trauma admissions ( $\mathrm{n}=1.1$ million) in the USA [3].

Clinical presentation is non-specific and may range from absence of symptoms to pain and these of severe hypovolaemic shock. Proper diagnostic approach is of paramount importance for these patients because of the high mortality of BTAIs [4].

With regards to diagnosis, there has been a shift from classic angiography, which used to be the diagnostic modality of choice in the past, to emergency CT scan. This shift represents one of the major advancements in the management of BTAIs and CT angiography is now the preferred screening tool and gold standard for diagnostic confirmation and delineation as well as evaluation and grading of these injuries [4-6].

Treatment of patients with BTAIs may be interventional (immediate or delayed, surgical or endovascular repair) or conservative (medical therapy), and this is largely dependent

*Address correspondence to this author at the Department of Cardiothoracic Surgery, University Hospital of Wales, Heath Park Campus, Cardiff, CF 14 4XW, UK; Tel: 0292074 7747; E-mail: gdimitrakakis@yahoo.com on clinical judgement on an individual basis. With regards to the best timing of intervention, the decision should be made based on the presence and severity of symptoms and related complications, comorbidities and the presence or absence of other injuries [4].

Interventional treatment for BTAIs can be either surgical [open repair (OR)] or endovascular [thoracic endovascular aortic repair (TEVAR)]; TEVAR started to gain popularity after the first reported case series of the use of thoracic stent grafts for thoracic aortic pathology by Dake et al. in 1994 [7].

Beyond the commonly-encountered perioperative complications, the repair of BTAIs may lead to more specific complications, such as paraplegia and stent endoleaks, which represent the most common complications of $\mathrm{OR}$ and TEVAR respectively.

Notably, paraplegia is substantially more common after OR than after TEVAR, and this is most likely due to clamping and prolonged hypotension and extension of aortic trauma in the former as well as the short segment of aorta stented in the latter and its relation to the blood supply of the spinal cord [5]. However, despite the favorable results of TEVAR over OR in terms of mortality and paraplegia, the durability and long-term complications of endovascularly repairing BTAIs still remain uncertain as only a limited number of studies that describe long-term results have been published $[8,9]$.

\section{PROGRESS IN THE MANAGEMENT OF BTAIs}

A report of paramount significance illustrating the important changes in clinical practice was published by Demetriades et al. (2008). The authors compare and analyse the findings of two studies conducted by the American Association 
for the Surgery of Trauma in 1997 and 2007 that describe the management of BTAIs [10].

In the first study, classic angiography was performed in $87 \%$ and CT scan in $34.8 \%$ of patients, while in the second one, only $8.3 \%$ patients underwent classic angiography due to the marked increase in the use of CT scan (93.3\%) [10].

The authors note three major shifts in the definitive treatment of BTAIs: 1) the time from admission to definitive treatment was significantly longer in 2007 compared with 1997 (mean $=54.6$ hours versus mean $=16.5$ hours respectively); 2) the treatment of choice shifted from open surgery in 1997 (100\% of cases) to TEVAR in 2007 (64.8\% of cases); 3) in 2007, bypass techniques were noted to be used more liberally during ORs than in 1997 [10].

These changes in the diagnostic work-up and interventional treatment of BTAIs seem to be beneficial, as mortality and procedure-related paraplegia dropped significantly between 1997 and 2007, from $22.0 \%$ to $13.0 \%$ and from $8.7 \%$ to $1.6 \%$ respectively. Furthermore, paraplegia rates in ORs exclusively fell significantly from $8.7 \%$ to $2.9 \%$ between the two studies, most likely due to the increasing use of cardiopulmonary bypass support, spinal cord protection, and sequential cross-clamping. The only negative outcome described was the increase in early graft-related complications from $0.5 \%$ in 1997 to $13.5 \%$ in 2007 (endoleaks, aortic puncture injuries, impairment of subclavian artery flow, strokes and paraplegia) [10].

\section{RELEVANT LITERATURE}

Recently published observational studies and metaanalyses favour the use of the endovascular method as definitive treatment over OR in patients with BTAIs and support delaying repair of the injuries where possible [11-25].

Six (6) meta-analyses were identified in the literature and all were in favour of TEVAR in terms of both mortality (odds ratio 0.31-0.61) and paraplegia (odds ratio 0.23-0.34) [11-16]. Further to the above parameters, Tang et al. (2008) reported lower stroke rates of TEVAR $(0.85 \%)$ compared with OR $(5.3 \%)$ and equal technical success rates between the two treatment methods, while Hoffer et al. (2008) reported a $4.2 \%$ incidence of endoleaks in BTAIs treated with TEVAR [9]. Apart from the overall lower procedure-related mortality of TEVAR compared with OR (odds ratio 0.31 ) described by Xenos et al. (2008), 30-day mortality was also significantly lower in the TEVAR group (odds ratio 0.44 ) in the same study [12].

Finally, Murad et al. (2011) included a "no treatment" group in their meta-analysis, which had higher mortality rates $(19 \%)$ than TEVAR $(9 \%)$ but lower than OR $(46 \%)$. The risk of spinal cord ischaemia and end-stage renal failure was higher in the OR group (9\% and $8 \%$ respectively) compared to TEVAR (3\% and 5\% respectively) and no treatment (3\% and $3 \%$ respectively) groups, and there was no difference in stroke rates among the three groups [13].

Two large prospective studies are also in support of the use of TEVAR compared with OR as the former treatment method yielded lower mortality rates $[17,18]$. In the study by Demetriades et al. (2008), mortality in the TEVAR group was lower in patients with and without extra-thoracic injuries (odds ratio 8.42) and additionally, fewer transfusion units (mean difference 4.98) were required for TEVAR patients. Paraplegia rates were similar in the two groups [17]. Azizzadeh and colleagues (2011) described an estimated odds ratio of 0.33 for complications (including in-hospital mortality) with TEVAR compared with OR, similar costs, and similar length of hospital stay [18].

In another prospective study by Demetriades et al. (2009), where early and late repair were compared, stable BTAI patients who underwent late repair had lower mortality rates (odds ratio 7.78) and similar complication rates. Finally, the late repair group had a longer mean ICU and hospital lengths of stay [19].

Interestingly, of the 6 large retrospective studies analysed, only 3 [Arthurs et al. (2009), Branco et al. (2014), Estrera et al. (2010)] found lower death rates in BTAIs repaired with TEVAR compared with those treated with OR [20-25].

Arthurs et al. (2009) performed a 5 year analysis of the National Trauma Data Bank (USA) and reported equal survival rates between the two groups, however TEVAR was superior to OR in terms of survival when repair was delayed (0\% vs. 12\%). Similar paraplegia rates in TEVAR and OR groups were described in the same study, however the latter group suffered higher rates of acute respiratory distress syndrome $(2 \%$ vs. $7 \%)$, pneumonia ( $12 \%$ vs. $18 \%)$, myocardial infarction (4\% vs. 25\%) and acute kidney injury (6\% vs. $10 \%$ ) [3]. Five years later, Branco et al. (2014), after a 9 year analysis of the same data bank, described favorable outcomes of the endovascular approach compared with OR in terms of in-hospital mortality $(12.9 \%$ vs. $22.4 \%)$ and sepsis (5.4\% vs. $7.5 \%)$ [20].

In the study by Estrera et al. (2010) that reported lower mortality rates of TEVAR $(0 \%)$ compared with OR $(14 \%$ with and $31 \%$ without distal aortic perfusion), delayed repair (mortality $2 \%$ ) was superior to early repair (mortality $28 \%$ ) and, specifically in the OR group, mortality and paraplegia rates were higher in those who underwent distal aortic perfusion (14\% and $0 \%$ respectively) compared with those who did not $(31 \%$ and $10 \%$ respectively). Paraplegia rates were similar between TEVAR and OR groups [21].

In a study by Patel et al. (2011) where freedom from reintervention was compared, zero patients required another procedure in the OR group $(0 \%)$ compared with 1 patient treated with TEVAR (6\%) [20]. According to Estrera and colleagues (2013), TEVAR was statistically superior to OR with cross-clamping but not to OR with distal aortic perfusion, in terms of survival $(4 \%, 31 \%$ and $14 \%$ respectively). In the same study survival at 1 and 5 years post-intervention was $76 \%$ and $75 \%$ respectively for OR, and $92 \%$ and $87 \%$ for TEVAR [23].

Finally, Di Eusanio et al. (2013) found that delayed repair was used as first-line treatment for BTAIs and was associated with a very low mortality (3.9\%). Comparing TEVAR and OR groups, mortality and paraplegia rates were not different [24]. 
Azizzadeh et al. (2014) supported that mid-term outcomes (median follow-up 2.3 years, range 0-7 years) of TEVAR make it a safe and durable method for BTAIs, having reported small percentages of in-hospital mortality $(5.0 \%)$, stroke $(2.4 \%)$, paraplegia $(0 \%)$, and device-related complications (2.4\%) [25].

A recent study by Canaud et al. (2015) described data of follow-up of minimum 10 years post-TEVAR (mean 11.6 years) with very encouraging results. The authors showed that the favorable outcomes of TEVAR over OR in terms of mortality and complications last over time, as none of the 53 patients with acute traumatic transection of the thoracic aorta treated endovasculalry died or had any device-related complications [9].

Karmy-Jones et al. (2011), who included 62 retrospective reviews and 6 meta-analyses in their well-presented systematic review (2005-2010), concluded that TEVAR had a lower mortality and lower incidences of paraplegia compared with OR although the former was performed in older patients, however, a statistically significant survival benefit was reported only in 4 papers [26].

The authors, considering the findings of Demetriades $e t$ al. (2009) described above, suggest delaying repair for patients with either significant injury or reversible physiologic derangement $[19,26]$.

With respect to paraplegia after TEVAR, Scali et al. (2014) identified 5 predictors that influence the risk of spinal cord ischaemia. The authors described age, aortic coverage length, Chronic Obstructive Pulmonary Disease, chronic kidney disease and hypertension determining the risk of post-TEVAR paraplegia and produced a simple clinical tool to assist decision-making about the choice of definitive treatment and guide the implementation of protective strategies [27].

\section{GUIDELINES}

For the treatment of BTAIs, recent clinical practice guidelines by the Society for Vascular Surgery advocate that TEVAR should be used preferentially over OR or nonoperative management, and repair should be performed urgently ( $<24$ hours). Expectant management is recommended for minimal aortic injuries with serial imaging for type I injuries, and TEVAR is advised for young patients, regardless of age, if anatomical criteria are permissive [28].

These latter recommendations are in accordance with the more recently-published guidelines of the Task Force for the Diagnosis and Treatment of Aortic Diseases of the ESC, that advise the use of TEVAR in suitable anatomies (Level of Evidence: C). With respect to diagnosis, upon suspicion of a traumatic aortic injury, including BTAIs, CT should be used and, if not available, TOE should be considered, according to the guidelines (Level of Evidence: C) [29].

Additionally, with regards to long-term surveillance and more specifically the detection of endoleaks, pseudoaneurysms and stent graft material-related complications, they recommend the combination of a chest X-ray with either MRI or CT scan. Although CT is currently the preferred modality, they advise considering the dangers of radiation, especially in younger patients, and suggest the use of MRI except in cases of magnetic resonance-incompatible grafts [29].

With respect to the use of TEVAR exclusively, the most recent guidelines suggest that TEVAR is indicated for patients with complete transection of the aortic wall and haemorrhage into the mediastinum and those with pseudocoarctation syndrome; according to the same guidelines, limited disruption of the aorta with intact intima and media should be managed expectantly with conservative management [30].

\section{CONCLUSION}

During the last years, there have been major, innovative advancements in the management of BTAIs. Published reports indicate that CT scans are now used as the diagnostic modality of choice.

Additionally, endovascular repair should be used in preference to open surgical repair or medical treatment, taking into consideration the lower mortality and paraplegia rates on one hand, and the anatomy, pathology and comorbidities of the other. The final decision should be made on an individual basis by a multidisciplinary approach regarding the type and timing of intervention.

Continued surveillance is essential for the early detection of potential complications and adverse effects and improvement of the design of the endografts is required for the avoidance of graft-related complications and longer survival of the grafts in BTAIs repaired with TEVAR. Finally, the absence of extensive long-term follow-up data for TEVAR should carefully be considered when the endovascular approach is chosen for definitive treatment of BTAIs.

\section{CONFLICT OF INTEREST}

The authors confirm that this article content has no conflict of interest.

\section{ACKNOWLEDGEMENTS}

Declared none.

\section{REFERENCES}

[1] Yamane BH, Tefera G, Hoch JR, Turnipseed WD, Acher CW. Blunt thoracic aortic injury: Open or stent graft repair? Surgery 2008; 144(4): 575-80.

[2] Fabian TC, Richardson JD, Croce MA, et al. Prospective study of blunt aortic injury: multicenter trial of the american association for the surgery of trauma. J Trauma 1997; 42: 374-83.

[3] Arthurs ZM, Starnes BW, Sohn VY, Singh N, Martin MJ, Andersen CA. Functional and survival outcomes in traumatic blunt thoracic aortic injuries: An analysis of the National Trauma Databank. J Vasc Surg 2009; 49(4): 988-94.

[4] O'Connor JV, Byrne C, Scalea TM, Griffith BP, Neschis DG. Vascular injuries after blunt chest trauma: diagnosis and management. Scand J Trauma Resusc Emerg Med 2009; 17: 42.

[5] Nzewi O, Slight RD, Zamvar V. Management of blunt thoracic aortic injury. Eur J Vasc Endovasc Surg 2006; 31: 18-27. 
[6] Sturm TJ, Hankins DG, Young G. Thoracic aortograghy following blunt chest trauma. Am J Emerg Med 1990; 8: 92-6.

[7] Dake MD, Miller DC, Semba CP, Mitchell S, Walker PJ, Liddell RP. Transluminal placement of endovascular stent-grafts for the treatment of descending thoracic aortic aneurysms. NEJM 1994; 331: 1729-34

[8] Mary-Ane C, Berthet J, Branchereau P, Mary H, Alric P. Endovascular repair of acute traumatic rupture of the thoracic aorta. Ann Thorac Surg 2003; 75: 1803-7.

[9] Canaud L, Marty-Ane C, Ziza V, Branchereu O, Alric P. Minimum 10-year follow-up of endovascular repair for acute traumatic transection of the thoracic aorta. J Thorac Cardiovasc Surg 2015; 149(3): 825-9.

[10] Demetriades D, Velmahos GC, Scalea TM, et al. Diagnosis and treatment of blunt thoracic aortic injuries: changing perspectives. J Trauma 2008; 64(6): 1415-8.

[11] Hoffer EK, Forauer AR, Silas AM, Gemery JM. Endovascular stent-graft or open surgical repair for blunt thoracic aortic trauma: systematic review. J Vasc Interv Radiol 2008; 19: 1153-64.

[12] Xenos ES, Abedi NN, Davenport DL, et al. Metaanalysis of endovascular vs. open repair for traumatic descending thoracic aortic rupture. J Vasc Surg 2008; 48(5): 1343-51.

[13] Xenos ES, Minion DJ, Davenport DL, et al. Endovascular versus open repair for descending thoracic aortic rupture: institutional experience and meta-analysis. Eur J Cardiothorac Surg 2009; 35: 282-

[14] Tang GL, Tehrani HY, Usman A, et al. Reduced mortality, paraplegia, and stroke with stent graft repair of blunt aortic transections: a modern meta-analysis. J Vasc Surg 2008; 47(3): 671-5.

[15] Takagi H, Kawai N, Umemoto T. A meta-analysis of comparative studies of endovascular versus open repair for blunt thoracic aortic injury. J Thorac Cardiovasc Surg 2008; 135: 1392-4.

[16] Murad MH, Rizvi AZ, Malgor R, et al. Comparative effectiveness of the treatments for thoracic aortic transection. J Vasc Surg 2011; 53(1): 193-9.

[17] Demetriades D, Velmahos GC, Scalea TM, et al. American Association for the Surgery of Trauma Thoracic Aortic Injury Study Group. Operative repair or endovascular stent graft in blunt traumatic thoracic aortic injuries: results of an American Association for the Surgery of Trauma Multicenter Study. J Trauma 2008; 64(3): 561-70.

[18] Azizzadeh A, Charlton-Ouw KM, Chen Z, et al. An outcome analysis of endovascular versus open repair of blunt traumatic aortic injuries. J Vasc Surg 2013; 57(1): 108-14.

[19] Demetriades D, Velmahos GC, Scalea TM, et al. Blunt traumatic thoracic aortic injuries: early or delayed repair--results of an
American Association for the Surgery of Trauma prospective study. J Trauma 2009; 66(4): 967-73.

[20] Branco BC, DuBose JJ, Zhan LX, et al. Trends and outcomes of endovascular therapy in the management of civilian vascular injuries. J Vasc Surg 2014; 60(5): 1297-307.

[21] Estrera AL, Gochnour DC, Azizzadeh A. et al. Progress in the treatment of blunt thoracic aortic injury: 12-year single-institution experience. Ann Thorac Surg 2010; 90(1): 64-71.

[22] Patel HJ, Hemmila MR, Williams DM, Diener AC, Deeb GM Late outcomes following open and endovascular repair of blunt thoracic aortic injury. J Vasc Surg 2011; 53(3): 615-20.

[23] Estrera AL, Miller CC III, Guajardo-Salinas G, et al. Update on blunt thoracic aortic injury: fifteen-year single-institution experience. J Thorac Cardiovasc Surg 2013; 145(3 Suppl): S154-S158.

[24] Di Eusanio M, Folesani G, Berretta P, et al. Delayed management of blunt traumatic aortic injury: open surgical versus endovascular repair. Ann Thorac Surg 2013; 95(5): 1591-97.

[25] Azizzadeh A, Ray HM, Dubose JJ, et al. Outcomes of endovascular repair for patients with blunt traumatic aortic injury. J Trauma Acute Care Surg 2014; 76(2): 510-6.

[26] Karmy-Jones R, Ferrigno L, Teso D, Long WB III, Shackford S. Endovascular repair compared with operative repair of traumatic rupture of the thoracic aorta: a nonsystematicreview and a plea for trauma-specific reporting guidelines. J Trauma. 2011; 71(4): 105972

[27] Scali ST, Wang SK, Freezor RJ, et al. Preoperative prediction of spinal cord ischemia after thoracic endovascular aortic repair. J Vasc Surg 2014; 60(6): 1481-90

[28] Lee WA, Matsumura JS, Mitchell RS, Farber MA, et al. Endovascular repair $\mathrm{f}$ traumatic thoracic aortic injury: clinical practice guidelines of the Society for Vascular Surgery. J Vasc Surg 2011; 53(1): 187-92.

[29] Erbel R, Aboyans V, Boileau C, et al. 2014 ESC Guidelines on the diagnosis and treatment of aortic diseases: Document covering acute and chronic aortic diseases of the thoracic and abdominal aorta of the adult. The Task Force for the Diagnosis and Treatment of Aortic Diseases of the European Society of Cardiology (ESC). Eur Heart J 2014; 35(41): 2873-926.

[30] Grabenwoger M, Alfonso F, Bachet J, et al. Thoracic Endovascular Repair (TEVAR) for the treatment of aortic diseases: a position statement from the European Association for Cardio-Thoracic Surgery (EACTS) and the European Society of Cardiology (ESC), in collaboration with the European Association of Percutaneous Cardiovascular Interventions (EAPCI). Eur Heart J 2012; 33(13): $1558-63$

(C) Challoumas and Dimitrakakis; Licensee Bentham Open.

This is an open access article licensed under the terms of the Creative Commons Attribution Non-Commercial License (http://creativecommons.org/licenses/by$\mathrm{nc} / 3.0 /$ ), which permits unrestricted, non-commercial use, distribution and reproduction in any medium, provided the work is properly cited. 